\title{
Consumidores, Designers e Gestores: aplicação do modelo da cadeia meios-fim para $o$ desenvolvimento de produtos de moda-vestuário
}

Consumers, Designers and Managers: application of meansend chain model for fashion-clothing product development

Maria Alice Vasconcelos Rocha

PhD; Universidade Federal Rural de Pernambuco modalice.br@gmail.com 


\section{Consumidores, Designers e Gestores: aplicação do modelo da cadeia meios-fim para o desenvolvimento de produtos de moda-vestuário}

\section{Consumers, Designers and Managers: application of means-end chain model for fashion-clothing product development}

\section{Maria Alice Vasconcelos Rocha}

\section{Resumo}

O objetivo deste estudo foi testar uma ferramenta metodológica apta a dar suporte à tomada de decisão de equipes de desenvolvimento de produtos. A abordagem considerou três principais interessados: Consumidores, Designers e Empresas. Análises qualitativas e quantitativas foram realizadas, tendo como base dados primários coletados no Reino Unido, Brasil e China. O modelo da Cadeia Meios-Fim de Gutman (1982), composto por Atributos, Benefícios e Valores foi utilizado. Os resultados demonstraram que Designers e Empresas estão distantes de atingir uma sinergia com Consumidores. $\mathrm{O}$ modelo utilizado demonstrou efetividade no processo de tomada de decisão em design de modavestuário.

Palavras - chave: Gestão do Design, Métodos de Pesquisa, Roupa

\begin{abstract}
The main aim of this study is to find a methodological tool able to support product development decision-making teams. The approach considers three main stakeholders: consumers, designers and companies. Qualitative and quantitative analyses were carried out based on primary data gathered in the UK, Brazil and China. The Gutman's Means-End Chain Model (1982), comprised of Attributes, Consequences and Values, was used for the analyses. The results demonstrate that designers and companies are far from achieving synergy with consumers. The Means-End Model blending stakeholder interests seems to be an effective tool to support the decisionmaking process in fashion-clothing design.
\end{abstract}

Keywords: Design Management, Research Methods, Garment. 


\section{Introdução}

Os processos de globalização da economia tem feito com que, sistematicamente, as empresas implementem planos para manter competitividade. Considerando, neste contexto, que o design é fator-chave para a cadeia têxtil e de confecções, se faz necessário reconhecer a pesquisa de métodos de design como um campo do saber rico em possibilidades de soluções. Adicionalmente, deve-se considerar como elementos agregadores à reflexão as mudanças ambientais e as tendências interconectadas como a globalização cultural (Dicken, 1999), o avanço da conectividade (Solomon, 2004), a importância da informação (Frings, 2002) e a busca pela sustentabilidade (Manzini and Vellozi, 2002).

No entanto, um dos aspectos mais complexos tem sido definir o que é a indústria da moda e a indústria do vestuário. As expectativas dos consumidores e a gama de produtos no mercado parecem contribuir negativamente para essa distinção. Originalmente derivadas da indústria têxtil, a combinação de moda e vestuário criou um universo único, e indissociável no ponto de vista do consumidor. Portanto, considerando que o produto de moda-vestuário é composto essencialmente por três pilares: a ergonomia, as tendências e a subjetividade, esta pesquisa persegue a multidisciplinaridade. Considera-se, ainda, para a investigação e análise, as equipes de designers e de gestores visto que as mesmas devem considerar tanto o ciclo de vida do produto e quanto os requisitos ligados a mudanças de comportamento do consumidor.

As características das roupas e suas relações com as percepções do usuário quanto à satisfação de suas necessidades é um fator mais que relevante no desenvolvimento de novos produtos. Para isso, é necessário compreender as pessoas por meio de uma abordagem holística, não somente considerando seus aspectos físicos ou cognitivos, mas também seus valores, estilos de vida, relacionamentos, desejos, medos, sonhos, etc., ou seja, tudo que nos faz seres humanos (Jordan, 2002).

\section{A Indústria da Moda}

Uma das indústrias que mais cresce no mundo é a da moda. Em mercados maduros, onde o crescimento é mais complexo, a abordagem para o seu desenvolvimento tem sido relacionada ao uso de tendências de comportamento de consumo aliado ao encurtamento do ciclo de vida dos produtos. No entanto, não há 
unanimidade na definição do que é a indústria da moda. Hoeks e Post (2006) dizem que o aspecto complementar que une moda e vestuário fica claro com as estações do ano: a moda, para ser moda precisa estar em voga mas o que materializa as mudanças fica óbvio por meio das roupas. Ainda de acordo com os autores, enquanto a indústria do vestuário vende produtos, a indústria da moda não comercializa objetos e sim significados. E é esta combinação que garante a satisfação das necessidades dos consumidores.

Originário da produção de têxteis, as indústrias do vestuário e da moda têm operado dentro da arena de design global e das informações fornecidas por diversas agências especializadas. Estudos sobre consumo tem fornecido acesso para o tipo de informação que as empresas mais carecem: sobre gostos, necessidades, desejos, atitudes, opiniões e os interesses dos consumidores e os grupos sociais mais relevantes (BRANCO ET AL., 2000).

Nas últimas duas décadas, a globalização se tornou uma questão cada vez mais importante. O Brasil, juntamente com a Rússia, Índia e China passou a ser chamado de BRIC, as quatro nações que juntos, de acordo com a Goldman Sachs relatam (1999) devem superar o atual G7 em termos econômicos nas próximas três ou quatro décadas. Adicionalmente, para que houvesse uma maior representação das nações emergentes e de mais um continente, a África do Sul foi acrescida em 2011, passando a ser conhecido como o bloco dos BRICS (RIBEIRO E MORAES, 2012). Isto significa que mais consumidores ansiosos se juntam à classe que compra de forma massiva (TRENDWATCHING, 2005).

\section{Alterando o Direcionamento da Gestão em Design}

A abordagem tradicional do desenvolvimento de produtos se baseia na habilidade das empresas em produzir e ofertar algo baseada na sua capacidade produtiva ou no seu registro de vendas bem sucedidas. Neste respeito, cabe ao marketing dar suporte ao estímulo de consumo de bens e serviços.

No entanto, o crescente poder do consumidor na dinâmica dos mercados contemporâneos, o ritmo de aceleração de mudanças e a necessidade de uma comunicação cada vez mais eficaz vinculada a tecnologias de informação, tem exigido que as empresas adotem novas abordagens. $\mathrm{O}$ respeito pelos direitos dos consumidores 
assim como e consideração das suas prioridades se tornou uma obrigação para empresas que buscam se adequar aos novos tempos.

Especialmente na indústria de vestuário de moda, onde o ciclo de vida de um produto é tão curto, as exigências do mercado precisam estar vinculadas diretamente ao processo de trabalho das equipes de projeto. Da mesma forma, devido à natureza dinâmica do processo de moda, as decisões precisam ser tomadas em nível de gestão.

Do ponto de vista dos consumidores, a abordagem baseada no usuário e em suas atitudes em busca pela satisfação de um produto ou serviço parece ser a mais eficaz pelos designers. Esta abordagem também faz a relação entre empresas e consumidores mais humana.

\section{Objetivos do Estudo}

Este trabalho visa agregar valor ao processo de planejamento estratégico para as empresas. Mas, para colocar a produção centrada no consumidor em ação, na maioria dos casos, é exigida uma mudança cultural dentro de empresas. Este processo também dá maior responsabilidade e controle aos designers, posicionando-os em como membros natos nas reuniões relacionadas a tomadas de decisão.

O principal objetivo deste estudo foi encontrar um instrumento metodológico capaz de apoiar as equipes na tomada de decisões de desenvolvimento de produto. A abordagem considera os três principais interessados do ciclo de consumo: consumidores, designers e empresas (gestores). O desafio se tornou em encontrar uma forma viável de medir as atitudes dos três detentores de interesse em relação aos produtos de moda-vestuário, de forma a facilitar a satisfação para o consumidor, trazer reconhecimento profissional para os designers de moda e possibilitar maior competitividade e rentabilidade para as empresas. As premissas do modelo de Cadeia de Meios-Fim (Gutman, 1982) foram adaptadas de uma ferramenta de marketing para uma ferramenta de gerenciamento de projeto e isso é apresentado como o resultado principal.

\section{Os Indicadores para o Consumo de Moda e Vestuário}

Considerando os objetivos desta pesquisa, faz-se necessária a adoção de critérios para a medição de preferências do consumo. Estudos anteriores a respeito do consumo de moda e vestuário realizados por Rocha (1999) e derivados de pesquisas qualitativas e quantitativas realizadas com uma amostra de 380 brasileiros revelaram a existência de 
28 indicadores que influenciam a escolha de consumo no Brasil. Uma pesquisa posterior realizada com consumidores britânicos estendeu os indicadores para 31 (Rocha et al., 2005). Os estudos com consumidores foram ampliados para a China, fornecendo insights e evidências para a construção de um modelo conceitual flexível, que finalmente foi composto por 38 Indicadores para o Consumo de Moda e Vestuário (Rocha, 2007), a saber: (1) adequação física; (2) aparência etária; (3) beleza; (4) bem estar; (5) caimento; (6) clima; (7) conforto; (8) convenções morais; (9) cor; (10) crenças; (11) destaque; (12) durabilidade; (13) elegância; (14) encantamento; (15) estilo pessoal; (16) exclusividade; (17) exibição do corpo; (18) conservação; (19) funcionalidade; (20 ) gênero oposto; (21) gosto; (22) humor/astral; (23) ideologia; (24) influência de celebridade; (25) julgamento de imagem; (26) marca; (27) mesmo gênero; (28) moda; (29) raízes; (30) ousadia; (31) preço; (32) profissão; (33) qualidade; (34) saúde; (35) sazonalidade; (36) sensualidade; (37) tecido e (38) versatilidade.

\section{O Modelo da Cadeia Meios-Fim}

A Teoria da Cadeia Meios-Fim desenvolvida por Gutman (1982) parece ser um modelo apropriado para classificar qualitativamente as atitudes dos consumidores por meio dos Indicadores para o Consumo de Moda e Vestuário (Rocha, 2007) com relação a bens e serviços visto que teoria apresenta sistematicamente uma hierarquia. $\mathrm{O}$ primeiro nível é composto por Atributos (A), que são as características, os componentes e as partes do elemento em análise. O nível seguinte é o das Consequências (C) que esses atributos proporcionam aos consumidores em termos de benefícios, e é mais subjetivo que o nível anterior. Segundo o autor, o no topo da cadeia estão os Valores $(\mathrm{V})$, que sinalizam os reais objetivos dos consumidores em relação aquele consumo específico (REYNOLD AND GUTMAN, 1984; WOODRUFF AND GARDIAL, 1996).

Os níveis do modelo representam os diversos fatores, do aspecto físico aos valores pessoais, proporcionando uma compreensão das razões por trás de uma escolha de consumo visto que a teoria parte do pressuposto que os consumidores enxergam os produtos ou serviços como meios para alcançar um determinado fim (MULVEY ET AL., 1994).

A maneira mais comum para realizar uma análise pelo modelo de cadeia de meiosfim é usando a técnica de escalonamento (laddering), ou seja, uma ferramenta 
conhecida para descrever uma estrutura cognitiva de uma pessoa ou grupos, baseado em entrevistas individuais. $\mathrm{O}$ escalonamento (laddering) é um método eficaz para analisar simultaneamente todos os aspectos do comportamento do consumidor que afetam a escolha do produto. O modelo adaptado oferece a oportunidade de comparar o grau de importância que designers e empresas (gestores) dão aos Indicadores que correspondem aos valores, consequências e atributos e então compará-los com aqueles atribuídos aos consumidores.

Existem três maneiras de perguntar aos consumidores quais os principais atributos de um produto: (1) classificação triádica - três produtos distintos são apresentados ao consumidor e ele deve identificar as semelhanças e diferenças entre eles; (2) diferenças entre preferências de consumo - onde o consumidor irá indicar seu produto preferido e (3) diferenças por ocasião - onde o consumidor, inserido em uma situação de consumo irá descrever as razões para uma escolha específica. Considerando que a teoria de Gutman baseia-se na resposta espontânea dos consumidores, na coleta de dados deste trabalho foi dada a oportunidade do consumidor adicionar novos indicadores relacionados ao seu processo de consumo.

Durante esse processo, às vezes, as respostas dos consumidores vieram numa ordenação aleatória no que diz respeito aos valores e consequências, o que reforçou a necessidade da construção de um mapa de valor hierárquico. O processo de análise de dados escalonados (laddering) é composto de quatro etapas: (1) análise de conteúdo (2) o desenvolvimento de matriz de implicação; (3) a construção do mapa de valor hierárquico e (4) a determinação de orientação perceptual dominante.

A etapa de análise de conteúdo é aquela onde o resultado é um conjunto de elementos relacionados a uma sequiência $\mathrm{A}-\mathrm{C}-\mathrm{V}$, expressando o raciocínio do consumidor em relação aos atributos, consequiências e valores. O papel do pesquisador é muito importante e intensivo visto que as demais fases serão baseadas em tais análises.

A fase seguinte, o desenvolvimento de matriz de implicação, é composto de ações para transferir todos os resultados da fase inicial para uma matriz de linhas e colunas usando codificação numérica. Neste momento, a agregação de presença/ausência de relação é feita, bem como uma combinação de métodos qualitativos e quantitativos.

A construção do mapa hierárquico valor oferece uma visualização das relações diretas e indiretas entre os elementos. Normalmente, nem todos os relacionamentos são mostrados, restando apenas aqueles acima do ponto de corte estabelecido pelo 
pesquisador. O processo baseia-se na estrutura da cadeia meios-fim a fim de facilitar a interpretação dos dados.

A última etapa do processo é a determinação da orientação perceptual dominante da cadeias meios-fim. Dos elementos base (Atributos) para os do topo (Valores) os números de relações internas são classificados e os fluxos com a maior pontuação são considerados como os mais importantes. Como o escopo desta pesquisa é de natureza exploratória e considera uma abordagem ampla, esta fase não foi considerada adequada.

\section{Materiais e Métodos}

Amostragem com Consumidores

Uma amostragem aleatória foi realizada com 264 consumidores (N) da Inglaterra (banco de dados UK-2004), 320 consumidores do Brasil (banco de dados BR-2004) e 227 consumidores da China (banco de dados CN-2004). Todos os consumidores tinham idade igual ou superior a 15 anos, considerando que este corte etário está relacionado com renda e interferência dos pais na escolha dos produtos. As amostras foram compostas de consumidores e consumidoras de diversas classes econômicas e graus de escolaridade. Nesse sentido, as análises buscaram encontrar similaridades e diferenças nas preferências dos consumidores britânicos, brasileiros e chineses para produtos de moda-vestuário. A abordagem considerou as diferenças entre um mercado maduro (o Reino Unido), um emergente ocidental (Brasil) e um emergente oriental (China).

O Reino Unido é um antigo e tradicional país mais quando comparado ao Brasil, e detém uma liderança no mundo em termos de economia, tendências de consumo e design. Até o século passado, o seu império colonial permitia que sua influência penetrasse em diferentes sociedades com facilidade. A sua política com as antigas colônias fez com que o Reino Unido seja, na atualidade, uma sociedade multicultural, composta por distintas etnias que carregam tanto valores distintos como valores comuns (CENSUS, 2001). Além disso, é preciso considerar como consequência a rebeldia e a ousadia dos jovens designers britânicos, fator determinante para a sua posição de vanguarda no mundo da moda.

Comparado com o Reino Unido, o Brasil é um país bastante jovem. As raízes culturais brasileiras são oriundas de Portugal, sob a influência de outras sociedades européias, das raízes culturais africanas e dos nativos indígenas, além de outros imigrantes de diversas partes do planeta, que com relativa facilidade se integraram e influenciaram ao jeito de ser brasileiro. Após a Segunda Guerra Mundial, os Estados Unidos se tornou a 
referência estrangeira para o povo brasileiro (CALDAS E ALCADIPANI, 2003). Mas, recentes mudanças no âmbito conjuntural fizeram surgir o reconhecimento da diversidade da cultura brasileira tanto internamente quanto no exterior, reforçando o conceito de brasilidade, embora ainda seja necessária a minimização da influência externa no inconsciente coletivo. Nos últimos anos a indústria brasileira de moda tem se nutrido de novos profissionais, exportado talentos e buscado um estilo brasileiro de consumir.

O país mais populoso do mundo, a China, tem um dos mercados que mais cresce na atualidade. A política de abertura da economia, iniciada em 1978, fez surgir nas duas últimas décadas o interesse por produtos e serviços importados e a ascensão da classe média (ANN, 2002). Na China ainda é possível perceber as diferenças entre Ocidente e Oriente, pois o valor atribuído às redes de relacionamento supera as expectativas de retorno financeiro e sua tradição e história de superação de adversidades é um importante aspecto do orgulho chinês, seja relacionado ao período imperial como ao período comunista. Cui e Liu (2000) sugerem uma imensa diversidade em atitudes, estilos de vida e padrões de consumo entre chineses de diferentes regiões do país, apesar dos efeitos da globalização. Segundo pesquisa da KSA (2004), o consumidor mais jovem e abastado claramente tem preferido marcas estrangeiras e perseguido o conceito de agregação do valor no que tange o design e produtos de moda.

O questionário foi composto de duas seções distintas: a primeira relacionada com o grau de importância que os consumidores atribuem aos elementos que influencia suas escolhas de roupas (os Indicadores para o Consumo de Moda-Vestuário) e a segunda parte relacionada com as informações do perfil social dos consumidores (Idade, Gênero, Renda, Religião, Etnicidade e Educação) e seu perfil corporal (Altura, Peso, Formato Corporal e Massa Corporal).

\section{Amostragem com Designers}

Uma pesquisa baseada em entrevistas roteirizadas foi realizada com designers de moda. Concretizou-se um total de vinte entrevistas, sendo seis entrevistas no Reino Unido, nove no Brasil e cinco na China. Para a amostra chinesa foi necessário o apoio de uma intérprete para o mandarim e o cantonês. Os designers foram convidados a participar da pesquisa com base em seus interesses, diversidade de trabalho e disponibilidade. Dentro de cada amostra nacional, foi visto como importante incluir designers de moda estabelecidos como conceituais, designers de moda estabelecidos 
como de marcas de difusão em grande escala e designers de moda da nova e emergente geração.

Todos os designers estavam inseridos no contexto de competitividade da indústria de moda em diferentes mercados: maduros ou emergentes, local ou global, ocidental ou global. Análises qualitativas e quantitativas foram utilizadas, no sentido de investigar as habilidades e a formação dos designers, bem como a posição da sua empresa, públicoalvo e previsões de expansão.

\section{Amostragem com Gestores}

Simultaneamente ao período de coleta de dados com os designers, realizou-se entrevistas com gestores de 20 empresas de moda no Reino Unido (6), Brasil (9) e China (5). Os critérios para a escolha das empresas foram similares àqueles adotados para a amostra com os designers, assim como os parâmetros relacionados à valoração do produto, estratégia de mercado, grupo estratégico e tamanho da empresa foram usados para apoiar a seleção inicial das empresas. Quando possível, o gestor máximo (CEO) foi o entrevistado, embora em alguns casos a entrevista tenha sido realizada com um gestor intermediário.

\section{Tratamento dos Dados}

Uma estrutura de banco de dados foi criada usando as informações originais coletados com consumidores, designers e empresas e colocados no software SPSS. Análises qualitativas e quantitativas foram realizadas com base nos dados primários recolhidos no Reino Unido, Brasil e China. Análise de conteúdo foi usada para a construção do mapa hierárquico de valor para o consumo de moda-vestuário usando a teoria da cadeia de meios-fim de Gutman (1982). Os dados relacionados ao grau de importância que consumidores, designers e gestores deram aos Indicadores para o Consumo de Moda e Vestuário foram ajustados para uma escala de tipo Likert de quatro pontos. A análise quantitativa deu suporte, ainda, às comparações entre os interessados (Consumidores, Designers e Gestores) no sentido de tornar evidências em insumos para recomendações.

\section{Resultados}


A categorização dos 38 Indicadores para o Consumo de Moda e Vestuário em Atributos, Consequências e Valores foi realizada, de acordo com o modelo de Cadeia Meios-Fim (Gutman, 1982).

Figura 1

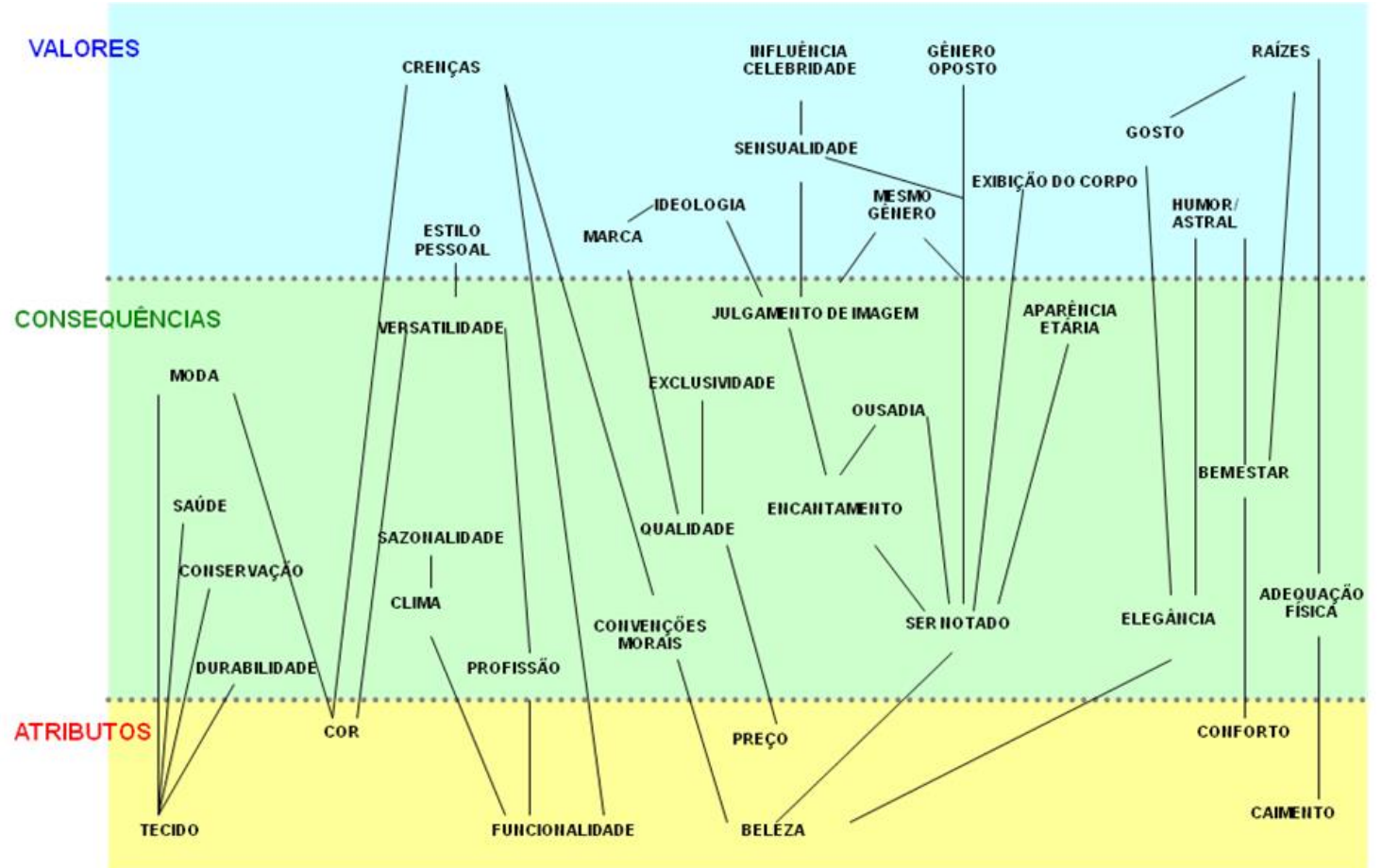

Figura 1 - Mapa Hierárquico de Valor para Produtos de Moda-Vestuário (ROCHA, 2007)

De acordo com Peter e Olson (1999) os consumidores vêem os produtos como um conjunto de atributos, que podem ser classificados em concreto (físicos, tangíveis) e abstratos (emocionais, intangíveis). Os autores afirmam também que os consumidores também veem os produtos como um conjunto de benefícios, considerando que essas consequências podem ser funcionais (resultados tangíveis de uma experiência direta do consumidor) ou psicológicos (resultados psicossociais relacionados ao consumo de um produto). Por outro lado os autores dizem, ainda, que os consumidores podem ver produtos como uma forma de satisfazer valores, que representam os objetivos finais do consumidor e são divididos em instrumental (ditados pela sociedade) e terminal (construídos individualmente).

\section{Analisando a Cadeia A-C-V}


Utilizando o modelo da Cadeia Meios-Fim, a análise a seguir é um estudo comparativo dos Indicadores de Consumo de Moda e Vestuário do ponto de vista dos consumidores, designers e empresas dos três países. É importante mencionar que todos os consumidores, designers e empresas tendem a maximizar o grau de importância que dão para um indicador, o que faz essas comparações bem equilibradas.

Os consumidores foram convidados a assinalar de 1 a 4 (discordo totalmente a concordo totalmente) o grau de concordância com os conceitos expressados no questionário baseados no Indicadores de Consumo de Moda e Vestuário. Mesmo existindo diferenças em torno da prevalência das categorias nas amostras nacionais deste estudo, as dez médias mais altas foram quase que unicamente a partir dos mesmos indicadores. Bem Estar foi o mais importante, seguido de Adequação Física e Caimento. Funcionalidade, Cor, Ser Notado, Versatilidade e Aparência Etária aparecem como as médias seguintes mais altas para as amostragens com todos os consumidores.

Do mesmo modo, designers e gestores foram convidados a marcar em uma escala Likert de 5 pontos, o grau de importância que eles atribuíam para seus produtos em relação aos Indicadores do Consumo de Moda e Vestuário. Os designers dos três países apresentaram ter em comum a mesma atenção para os seguintes indicadores nesta ordem: Estilo Pessoal, Qualidade, Gosto e Beleza. Na opinião dos consumidores, Estilo Pessoal apareceu numa posição de classificação relativamente baixa, o que indica uma falta de "sintonia" entre designers e consumidores. Para os designers britânicos Caimento foi o indicador mais importante, a Beleza foi é mais importante para os designers brasileiros e Conforto foi o indicador que os designers chineses deram maior atenção.

Comparando os resultados dos consumidores com as das empresas (gestores), é possível encontrar divergências no grau de importância atribuída aos indicadores. Devido ao tamanho da amostra com as empresas e a intenção de realizar uma análise global da indústria, os resultados dos três países foram combinados. Para as empresas britânicas, brasileiras e chinesas, o indicador mais importante foi o Caimento. Embora para as empresas, a Qualidade seja um dos indicadores mais importantes, este indicador não apresentou um ranking elevado para os consumidores. Um resultado semelhante é observado com o indicador Marca, o que parece revelar que as empresas estão colocando sua energia em indicadores que não são os mais significativos para os consumidores. 
Alguns indicadores controversos como Crenças e Raízes apresentaram uma classificação muito baixa, especialmente na amostragem com designers e gestores. Este resultado não significa que eles não sejam importantes para os consumidores, mas sinaliza que outros aspectos sejam muito mais importantes.

O primeiro ponto de reflexão está relacionado com os atributos de uma peça de roupa. Os indicadores - Tecido, Função, Conforto, Caimento, Cor, Beleza e Preço estão incorporados no conceito de um produto e se relacionam aos parâmetros tangíveis. O Gráfico 1, a seguir, compara os valores médios da frequência agregada (UK + BR + $\mathrm{CN}$ ) dos atributos julgados pelos três grupos alvo: consumidores, designers e empresas (gestores). Para os consumidores, a questão estava relacionada com o grau de importância que dão aos atributos, para os designers e os gestores, a pergunta foi qual o grau de importância que eles acham que seus consumidores dão para esses atributos. É interessante salientar que designers e gestores têm uma opinião bastante semelhante sobre os atributos.

Por outro lado, há uma distância significativa entre as opiniões dos consumidores e a opinião que designers e gestores consideram ser a dos consumidores. Isto é particularmente verdadeiro em relação à Funcionalidade, Preço e Cor. Por outro lado, Beleza e Conforto parecem ter uma importância muito maior para os designers que para os consumidores.
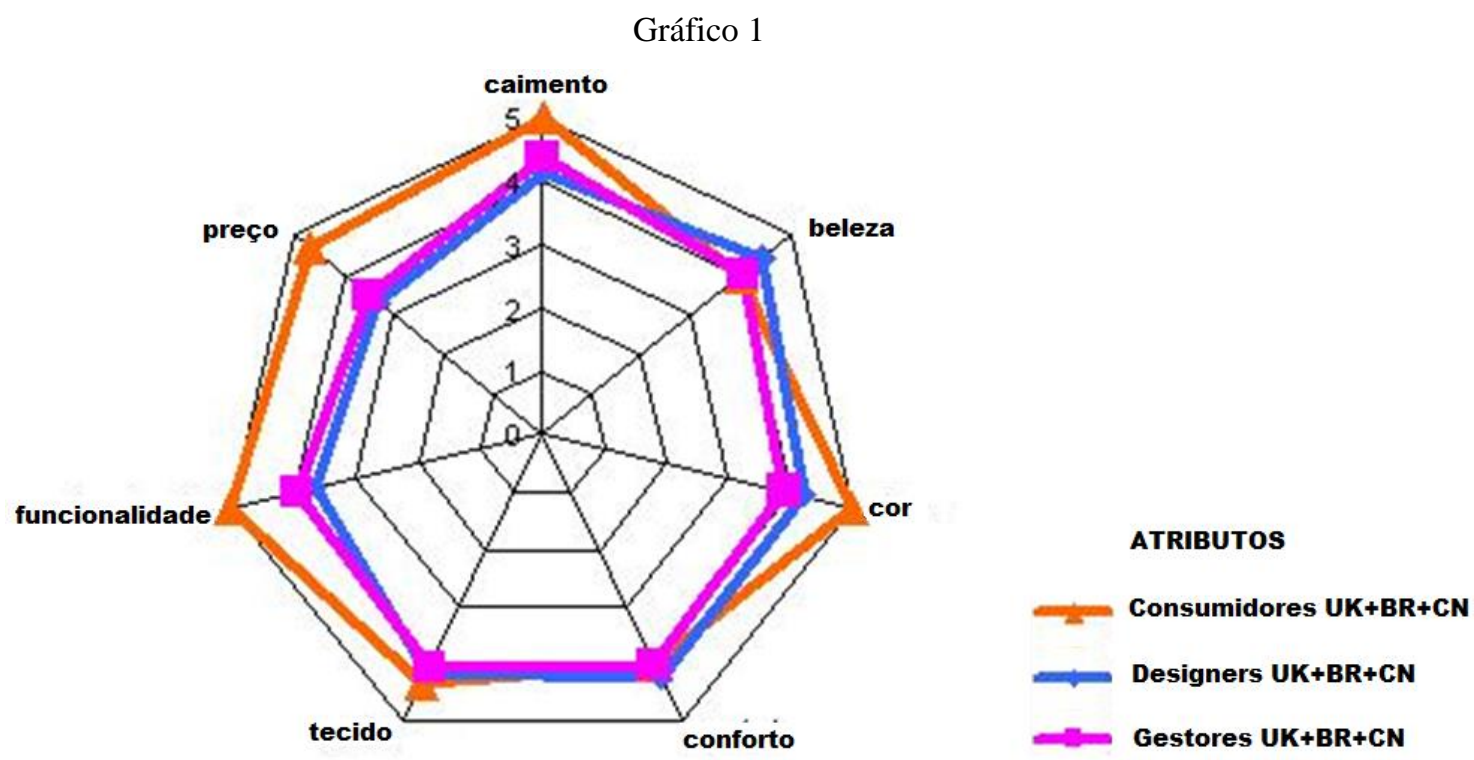

Gráfico 1 - Atributos para o Consumo de Moda-Vestuário segundo Consumidores, Designers e Gestores 
A análise dos dados relacionados às Consequências dentro da Cadeia Meios-Fim também revelou alguns pontos para reflexão (Gráfico 2). Os consumidores deram o escore máximo para cinco indicadores: Versatilidade, Bem Estar, Aparência Etária, Ser Notado e Adequação Física. Saúde foi um indicador subestimado pelos gestores, o que pode significar uma baixa adesão das empresas de moda para responsabilidade social.

Designers não valorizaram o indicador Convenções Morais, quando comparado com os outros dois grupos-alvo e Qualidade foi o indicador menos importante dentre aqueles pertencentes às consequências na Cadeia Meios-Fim, em especial para os consumidores. Este fato não significa que os consumidores não estejam interessados na qualidade do produto, mas possivelmente pode ser uma consequência do curto ciclo de vida de um produto de moda-vestuário, sua sazonalidade e, consequentemente, a ampla disseminação de um baixo padrão para esse tipo de produto. Outra constatação interessante está relacionada à Adequação Física: os designers, aqueles que deveriam estar considerando o corpo humano como o suporte para as roupas e a sua razão de existência (na medida que um produto só se torna roupa se houver um corpo para vestilo), foi o grupo que deu menos valor a este aspecto.

Gráfico 2

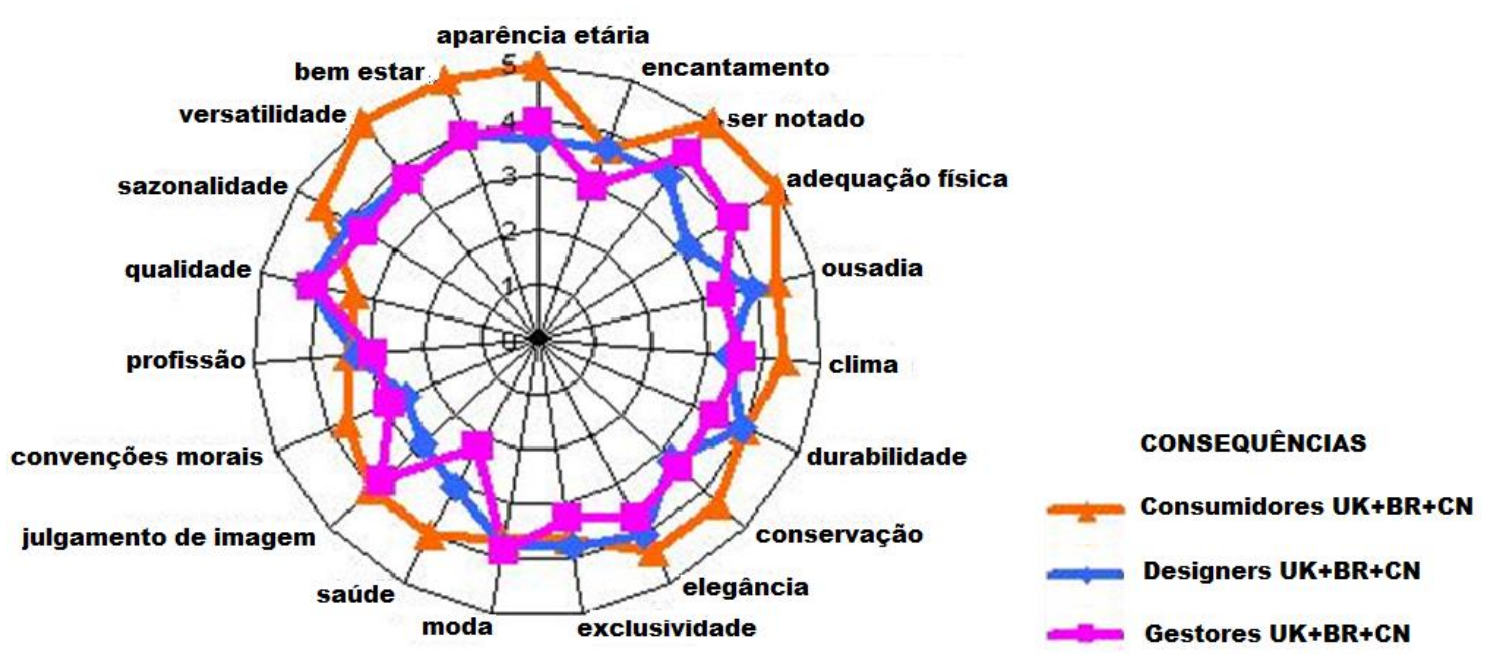

Gráfico 2 - Consequências para o Consumo de Moda-Vestuário segundo Consumidores, Designers e Gestores 
A análise dos Valores dentro de uma Cadeia Meios-Fim, apresentada no Gráfico 3, mostrou o resultado mais heterogêneo em comparação com aqueles dos atributos e consequências. Alguns valores foram superestimados por designers e gestores quando comparados às opiniões dos consumidores. Por outro lado, as empresas (gestores) subestimaram o valor da Ideologia para os consumidores, embora eles, seguido de perto pelosdesigners, deram valor substancial à Marca. Isto pode explicar o aumento do branding como tomada de decisão estratégica para as empresas. No entanto, Marca teve o valor relativamente pouco importante entre os consumidores.

Gráfico 3

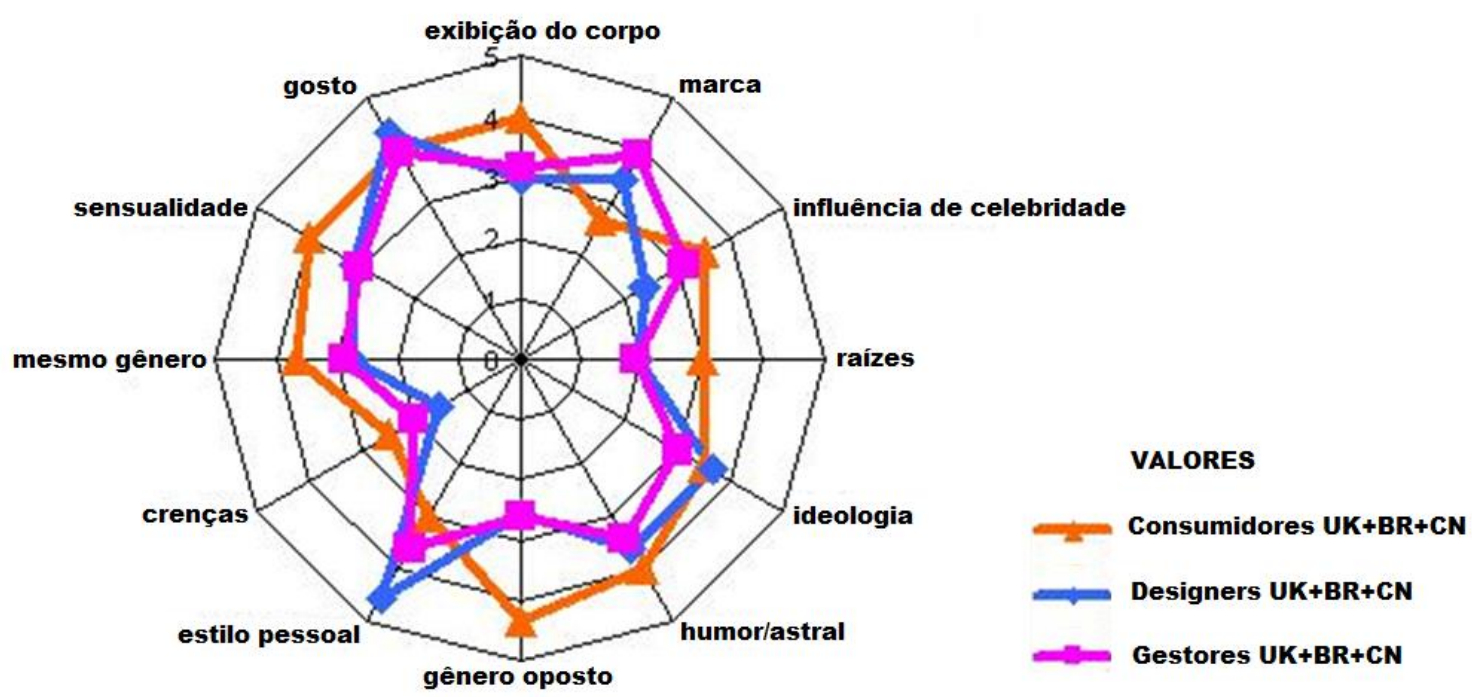

Gráfico 3 - Valores para o Consumo de Moda-Vestuário segundo Consumidores, Designers e

Gestores

Alguns resultados podem trazer, ainda, outros pontos para reflexão quanto às práticas no desenvolvimento de produtos. As respostas dos designers demonstram haver muita importância para o Estilo Pessoal, possivelmente, como uma consequência direta de suas próprias individualidades expressadas por meio do processo criativo, dando especial atenção ao processo autoral. Adicionalmente, o indicador Gosto, também, talvez por ser subjetivo, tenha recebido um maior escore pelos designers. Por outro lado, os indicadores Crenças e Influência de Celebridade foram valores especialmente subestimados pelos designers.

Surpreendentemente, o indicador Sexo Oposto, foi o valor mais importante para os consumidores, o que indica que as consumidoras, parecem estar constantemente atentas 
às pessoas que estão no seu entorno, especialmente se elas são pretendentes a parceiros. Os resultados indicam que o mesmo acontece com os consumidores masculinos quando em um ambiente com mulheres. No entanto, vale salientar que a pesquisa não considerou questões específicas quanto à orientação sexual, o que inviabilizou a possibilidade de comentários sobre atitudes gays neste contexto.

\section{Considerações}

Ao considerar o ponto de vista do consumidor, as abordagens usadas pelos designers parecem ser as mais eficazes para a busca por satisfação. Designers têm, em geral, atitudes e conhecimento baseado no usuário. No entanto, os resultados indicaram que os designers de moda da amostra parecem não ter acesso a informações adequadas sobre as reais necessidades do consumidor. As razões para isto podem variar desde designers que atuam em grandes marcas de difusão, cujos dados são fornecidos pelos departamentos de marketing, a designers vinculados a marcas conceituais, onde as ideias do diretor criativo são a essência do projeto.

Há evidências que sugerem que os consumidores não estão satisfeitos com o desempenho das empresas de moda. Os gestores talvez precisem se desprender de ideias preconcebidas sobre os estereótipos dos consumidores e agregar valor através de produtos de moda que transcendam idades, tamanhos, classes, crenças, raças, etc. Os resultados sugerem que a indústria da moda precisa estar mais atenta aos indicadores de consumo quando da segmentação dos consumidores, especialmente devido à diversidade crescente de perfis.

Sugere-se ainda que os gestores precisam compreender melhor as culturas e as diferenças estéticas, criando produtos de moda que transcendam as distintas formas de viver. Esta abordagem deve melhorar o relacionamento entre empresas e consumidores e deve ajudar no desenvolvimento de melhores produtos de moda por meio de tomada de decisões mais focadas e técnicas. Os resultados indicam ainda da necessidade de uma mudança dramática nas empresas de moda-vestuário no sentido de que seus negócios sejam melhor gerenciados no que tange o desenvolvimento de produtos para garantir um crescimento futuro ou sucesso comercial.

A medição contínua dos Atributos, Consequências e Valores dentro de uma Cadeia Meios-Fim é sugerida como uma forma inovadora para focar diferentes tipos de consumidores. $\mathrm{O}$ modelo oferece a possibilidade de se trabalhar com dados qualitativos 
e quantitativos de maneira complementar e mais assertiva. As informações podem ser facilmente coletadas, visto que a análise qualitativa pode ser alimentada por dados obtidos em grupos focais com consumidores e os Indicadores podem ser medidos por inquéritos vinculados ao cadastramento do consumidor a um cartão de fidelidade ou qualquer a tipo de enquete. Sugere-se, no entanto, que estas medições sejam feitas sistematicamente, para que as eventuais mudanças quanto às preferências possam ser antecipadamente identificadas.

\section{Recomendações}

O processo de tomada de decisão de uma empresa de moda precisa considerar não somente o relatório de venda ou as tendências de mercado, mas também uma constante atualização de informação referente ao consumidor e uma análise cruzada com os pensamentos dos designers. Esta prática pode melhorar a satisfação do consumidor e deve oferecer mais responsabilidade e distinção aos profissionais dentro da equipe de desenvolvimento de produto.

A ideia da análise de um produto de moda com base em Atributos, Consequências e Valores pode, não somente, ser inovadora, mas também dar a oportunidade para que todas as partes interessadas sejam capazes de antecipar quais as roupas que devem ser tornar objetos de desejo e seus porquês.

O modelo da Cadeia Meios-Fim foi criado, basicamente, para a análise do consumidor segundo a visão do marketing. No entanto, este estudo mostra os benefícios que a adoção deste método pode trazer para a avaliação do processo de desenvolvimento de produto. $\mathrm{O}$ modelo tentou criar uma ligação entre atributos e valores percebidos em um produto. A utilização de indicadores de pesquisa qualitativa categorizada pode ajudar no processo de contabilização dos dados quantitativos relacionados a práticas cotidianas de tomada de decisão.

\section{Limitações e Implicações}

A diferença considerável entre a quantidade de entrevistados dentro da amostra com consumidores em relação às amostras com designers e gestores sugere, possivelmente, uma maior precisão nos resultados do consumidor. Mesmo assim, essa 
proporção representa com confiabilidade o cenário real dentro da indústria da moda contemporânea.

As amostras foram limitadas a três países. Restrições relacionadas ao processo de amostragem garantem o controle do foco, mas, por outro lado, limita a aplicação dos resultados. No entanto, os grupos demográficos estudados são significativos na investigação de tendências globais, incluindo mercados maduros e emergentes, sejam eles de culturas ocidental ou oriental. É certo que a temática não se esgota aqui, e que restam inúmeras oportunidades para novas pesquisas, sejam em outros territórios, públicos específicos ou em outras áreas de atividade relacionadas ou não à gestão do design na indústria da moda.

Artigo recebido em Julho de 2015. Aprovado em Setembro de 2015

DOI:http://dx.doi.org/105965/1982615×08172016048

\section{Referências}

BRANCO, J.; PROVIDÊNCIA, F.; PINTO, C. \& BRANCO, V. Design research for small and medium-sized enterprises. Milan, Italy: Design plus Research (D+R ejournal), v. 1, 2000. http://pcsiwa12.rett.polimi.it/ phddi/uk/01/dpr00/intro.htm (acesso em 20 Jan 2006).

CALDAS, M. \& ALCADIPANI, R. Post-Colonialism in Latin American Management: The genesis and trail of North American Reference in Brazilian Culture and Management. Available at CMS Conference Proceedings, 2003. http://www.mngt.waikato.ac.nz/research/ ejrot/cmsconference/2003/abstracts/postcolonial/Caldas.pdf (acesso 20 Jan 2005).

CENSUS 2001 National Statistics. The Classification of Ethnic Groups, 2001. Available at http://www.statistics.gov.uk/about/Classifications/ns_ethnic_classification.asp (acesso 23 Fev 2005). 
CUI, G. \& LIU, Q. Regional Market Segments of China: opportunities and Barriers in a Big Emerging Market, Journal of Consumer Marketing, v01 n17, pp.55-72, 2000.

DICKEN, P. Global Shift: Transforming the World Economic. Chapter 9, "Fabricacting fashion": the textiles and clothing industries. London: Paul Chapman, 1999.

FRINGS, G. S. Fashion from concept to consumer. Upper Saddle River, NJ: Prentice Hall, 2002.

GUTMAN, J. A means-end chain model based on consumer categorization processes. Journal of Marketing, Volume 46 Issue1, pp.60-72, 1982.

JORDAN, P. W. Designing Pleasurable Products: an introduction to the new human factors. London: Taylor \& Francis, 2002.

MANZINI, E \& VELlOZI, C. O Desenvolvimento de Produtos Sustentaveis: os requisitos ambientais dos produtos industriais. Sao Paulo: USP, 2002.

MULVEY, M. S.; OLSON, J. C. \& CELSI, R. L. Exploring the Relationships between Means End Knowledge and Involvement. Advances in Consumer Research 21, 51-57, 1994.

PETER, J. P. \& OLSON, J. C. Consumer behavior and marketing strategy. 5. ed. Boston: Irwin McGraw-Hill, 1999.

REYNOLDS, T. \& GUTMAN, J. Advertising is image management. Journal of Advertising Research, p. 27-37, fev/mar, 1984.

RIBEIRO, E. J. \& MORAES, R. F. DE BRIC A BRICS: como a África do Sul ingressou em um clube de gigantes. Contexto Internacional. Volume 37. Número 1. Rio de Janeiro. Jan/Jun, 2015. 
ROCHA, M. A. V. Contribuição ao desenvolvimento de uma metodologia para a caracterização do comportamento do consumidor da indústria do vestuário: uma abordagem segundo Maslow. Master of Science in Production Engineering Dissertation, Recife, Universidade Federal de Pernambuco, 1999.

ROCHA, M. A. V.; HAMMOND, L. \& HAWKINS, D. Age, gender and national factors in fashion consumption. Journal of Fashion Marketing and Management, Volume 9 Issue 4, pp. 380-390, 2005.

SOLOMON, M. R. Consumer Behaviour: Buying, Having and Being. Upper Saddle River, New Jersey: Prentice Hall, 2004.

TRENDWATCHING. www.trendwatching.com (acesso 20 Set 2005).

WOODRUFF, R. B. \& GARDIAL, S. F. Know your customer: new approaches to understanding customer value and satisfaction. Malden: Blackwell Business, 1996. 